\title{
The Use of Fourier Infrared Spectroscopy and Laser - Raman Spectroscopy in Bladder Malignancy Diagnosis, A comparative Study
}

\author{
Essam G. Ahmed \\ Department of Physics, College of Science and Technology, Shendi University \\ PO box 142, Shendi, Republic of Sudan \\ Tel: 2499-1891-0730 E-mail: essamahmed173@hotmail.com \\ Nafie A. Al-Muslet (Corresponding author) \\ Institute of Laser, Sudan University of Science and Technology \\ Republic of Sudan \\ Tel: 2499-2287-4334Ｅ-mail:mnmfa2008@yahoo.com \\ Mubarak M. Ahmed \\ Institute of Laser - Sudan University of Science and Technology \\ Republic of Sudan \\ M. A. Moharam \& Waleed Musaad \\ Spectroscopy Department, Physics Division, National Research Center \\ Dokki, Giza, Egypt
}

\begin{abstract}
Bladder cancer is one of the most common cancers in Africa. It takes several days to reach a diagnosis using histological examinations of specimens obtained by endoscope, which increases the medical expense. Spectroscopic analysis of bladder cancer tissues has received considerable attention due to its sensitivity to biochemical variations in the samples. The present study investigated the use of FTIR and laser Raman spectrometer as diagnose tools of bladder cancer. Fourteen bladder samples were collected from 7 patients during surgery from different hospitals without any pretreatment. FTIR, with a ceramic source, was used to differentiate between normal and cancerous bladder tissues via the change in the spectra of these samples. The investigations detected obvious spectroscopic change in the proteins $\left(1650,1550 \mathrm{~cm}^{-1}\right)$, lipids $\left(2925,2850 \mathrm{~cm}^{-1}\right)$ and nucleic acid $\left(1080,1236 \mathrm{~cm}^{-1}\right)$.

With FT Raman spectrometer supplied with Nd:YAG laser, as an excitation light source, samples were studied and significant differences between the normal and cancerous bladder tissues were found around Raman shifts of $1650 \mathrm{~cm}^{-1}, 1440 \mathrm{~cm}^{-1}, 1270 \mathrm{~cm}^{-1}$ and $1080 \mathrm{~cm}^{-1}$. The comparison between the two techniques showed that Raman spectroscopy holds much promising as a rapid, sensitive, nondestructive method, and easy to use as an alternative method for identification and diagnosis of bladder cancerous tissues.
\end{abstract}

Keywords: FTIR spectroscopy, Laser Raman spectroscopy, Diagnosis of bladder malignancy, Spectroscopic techniques in medical diagnosis

\section{Introduction}

Infrared spectroscopy is certainly one of the most important analytical techniques available to today's scientists. One of the great advantages of infrared spectroscopy is that virtually any sample in virtually any state may be studied. Liquids, solutions, pastes, powders, films, fibers, gases and surfaces can all be examined with a judicious choice of sampling technique (Stuart, 2004). Infrared spectroscopy is a technique based on the vibrations of the atoms of a molecule. An infrared spectrum is commonly obtained by passing infrared radiation 
through a sample and determining what fraction of the incident radiation is absorbed at a particular energy (.Nakamoto, 2009). Because chemical bonds absorb infrared energy at specific frequencies, the basic structure of compounds can be determined by spectral location of their IR absorptions. The plot of a compound's IR transmission vs. frequency is its fingerprint, which when compared to reference spectra identifies the material.

On the other hand, Raman spectroscopy is a spectroscopic method based on light scattering from molecules in the sample. This technique is complementary to IR spectroscopy. It offers various advantages over MIR and NIR spectroscopy. Since water is a weak scatterer in the visible range, no special accessories are needed for measuring aqueous solutions. Furthermore, atmospheric gases are very weak scatterers, therefore purging of the Raman instrument is not needed. Ordinary glass is transparent in the visible and near infrared spectral regions, where Raman spectra are excited, so inexpensive liquid sample cells made from glass can be used for most Raman measurements. For remote analysis glass fiber optics can be used. The standard Raman spectral range extends down to $10 \mathrm{~cm}^{-1}$, so the technique is ideal for both organic and inorganic samples. The limitations of Raman spectroscopy in comparison to IR are sensitivity and undesired fluorescence (Hammes, 2005).

A human body, on a simple level, is composed primarily of water, proteins, nucleic acids, lipids and carbohydrates. Changes in the body, leading to diseases such as cancer, are thought to be due to some biochemical changes in one or all of these components. If vibrational spectra are sensitive to the structure of these components, then they too must change with the diseased state. Since the pioneering work of Elliott and Ambrose1 in 1950 for proteins and Blout and Fields in 1949 for nucleic acids, infrared (IR) and Raman spectroscopy have in fact been shown to be very sensitive to the conformation of these biological building blocks (Hammes, 2005).

When tissue is illuminated with laser light, photons interact with intermolecular bonds present within the tissue. When occurs, the photon donates energy to or receives energy from the bond, producing a change in the bond's vibrational state. When it subsequently exits the tissue, the photon has an altered energy level and, therefore, has a different wavelength compared to the original laser light. This change in the photon's energy is known as the 'Raman shift' and is measured in wavenumbers. Photons interacting with different biochemical bonds within the tissue, undergo different Raman shifts, which taken together, form the 'Raman spectrum'. The Raman spectrum is a direct function of the molecular composition of the tissue and can give a truly objective picture of it.

Histopathologists are able to provide acceptable classification into large subgroups of epithelial cancer and noncancer. However, while pathologists can demonstrate acceptable levels of agreement for the major comparative groups of cancer against negative cases, the division into subgroups of normal, mild pre-cancerous change, severe pre-cancerous change, and cancer has revealed a poorer level of agreement. In this sense, Raman technique would be able to perform quantitative and qualitative analysis, since it shows high sensitivity to small biochemical changes in biological tissues (Andrade et al., 2007).

\section{Materials and methods}

The collected tissues were investigated spectroscopically using Fourier Transform Infrared Spectrometer (FTIR) and Fourier Transform Raman Spectrometer (FT Raman).

The FTIR used is (FTIR-430, Jascow, Japan). This instrument has a ceramic IR source, KBr beam splitter, and DLATGS IR detector. The FTIR spectra of the samples were obtained in the spectral range 4000 to $400 \mathrm{~cm}^{-1}$ with a scanning speed of $2 \mathrm{~mm} / \mathrm{sec}$ and resolution of $4 \mathrm{~cm}^{-1}$.

The FT-Raman measurements were carried out by using the Nexus 670 FT- Raman spectrometer (Nicolet, USA). The excitation source in the FT Raman module is Nd-YAG laser. This laser emits continuous radiation at wavelength of $1064 \mathrm{~nm}$ and has a maximum power level of approximately $1.5 \mathrm{~W}$ at the sample. The installed detector in the laser Raman module is InGaAs, which is an air cooled detector. The used sample configuration is $180^{\circ}$ reflective with fully motorized sample position adjustment, with an NMR tube sample holder. The entire laser Raman spectra were collected in the spectral range from 3700 to $98 \mathrm{~cm}^{-1}$.

Fourteen fresh tissues of cancerous bladder and normal bladder tissues were obtained from 7 patients in many hospitals. The tissues were preserved in 10\% formaldehyde solution and sampled immediately after removing during the operations. Two pieces of the tissues, each of about $3 \mathrm{~cm}$ in diameter, were taken. One was cut off from the center of the lesion and the other was from the distant edge of the removed tissues. Each tissue was divided into two equal parts, one was preserved in $10 \%$ formaldehyde solution and the other was fixed with $10 \%$ formalin, embedded in paraffin and stained with hematoxylin for pathological examination. All the patients were diagnosed by physicians before operation as Squamous and Transitional cell carcinoma with endoscopic biopsy. 
Normal and cancer tissues were cut into small sizes (approximately $2 \mathrm{~mm}$ ) and were put in vacuum container beside silica jell for 3 days to absorb $\mathrm{H}_{2} \mathrm{O}$ in order to make the tissues dry for FTIR investigation.

A very small amount of the dried tissue, approximately $(2-3 \mathrm{mg})$, was finely grinded and intimately mixed with approximately $200 \mathrm{mg}$ of dry $(\mathrm{KBr})$ powder. Grinding and mixing were done with an agate mortar and pestle. Then the samples were placed between two disks and put under mechanical pressure. The pressure was 20 tons fixed for several minutes before removing the $\mathrm{KBr}$ disk formed. Re-crystallization of the $\mathrm{KBr}$ results in a clear glassy disk of about $1 \mathrm{~mm}$ thick. This disk is now ready to be analyzed by transmission. Then the disk was placed in the sample holder ready for scanning. A total of fourteen FTIR spectra were obtained from the normal and cancer samples. All measurements were carried out under room light and at room temperature.

On the other hand, Raman spectra were measured at different positions for each sample. Normal and cancer tissues were cut into small pieces and were put in vacuum container beside silica jell for few hours until the tissue become solid. A powder grinding was done with an agate mortar and pestle, powder sample was put in NMR tube sample holder. The spectra were recorded by a Nexus 670 Laser Raman spectrometer, no special sample preparation was needed in the experiment. A total of 64 scans were recorded at a resolution of $4 \mathrm{~cm}^{-1}$ in the region from 1800 to $200 \mathrm{~cm}^{-1}$. The laser power used was $0.5 \mathrm{~W}$. The spectra were processed using the computer program "Omnic E.S.P. Software, Version 5.2" provided by Nicolet, USA.

\section{Results and Discussion}

The experimental results were represented in this section. Examples of the recorded spectra are shown in figures below.

\subsection{Results of FTIR spectroscopy}

Figures (1) to (4) show examples from the spectra collected for the normal and cancerous tissues using FTIR-430 spectrometer.

In figures (1) to (4), the main spectral contributions are assigned to proteins around $3300,1650,1550,1450$, 1400 and $1240 \mathrm{~cm}^{-1}$ and lipids around 3000, 2930, 2925, 2850, 1740, and $1450 \mathrm{~cm}^{-1}$ (Qing-Bo et al., 2005). The bands around $1236 \mathrm{~cm}^{-1}$ and $1080 \mathrm{~cm}^{-1}$ are due mainly to the asymmetric and symmetric phosphate stretching mode due to nucleic acids, respectively (Naumann, 1998). The bands observed around $1200 \mathrm{~cm}^{-1}$ and $1030 \mathrm{~cm}^{-1}$ are arising from $\mathrm{C}-\mathrm{OH}$ stretching vibrations of collagen carbohydrate moieties, $\mathrm{C}-\mathrm{N}$ stretching vibrations of the collagen backbone and $\mathrm{CH}_{2}$ wagging vibrations of collagen side chains ( $\mathrm{Li}$ et al. 2002, Venkatachalam et al. 2008). In addition to lipids, proteins and nucleic acids, carbohydrates are also presented in all cells. The major absorption found in the 1000-1200 $\mathrm{cm}^{-1}$ region is for carbohydrate (Jilie, 2007, Farshad et al. 2007). The peaks positions and modes assignment of the main FTIR bands, for normal and cancer bladder tissues, are illustrated in table (1).

The weaker protein bands at 1450 and $1400 \mathrm{~cm}^{-1}$ are associated with the asymmetric and symmetric $\mathrm{CH}_{3}$ bending vibrations. The peaks at 1080 and $1236 \mathrm{~cm}^{-1}$ are attributed to $\mathrm{PO}_{2}$ (Nucleic acids), and the bands at 2925 and $2850 \mathrm{~cm}^{-1}$ are $\mathrm{CH}_{2}, \mathrm{CH}_{3}$ stretching vibrations of phospholipids (Qing-Bo et al. 2005).

Significant differences were found between normal and malignant bladder tissues in the FTIR spectra. Through the spectral analysis, the spectral characteristics of malignancy were as follows: From the FTIR spectra, it can be seen that the cancerous tissue had higher absorption in the $\mathrm{N}-\mathrm{H}$ region $\left(3500-3000 \mathrm{~cm}^{-1}\right)$, amide I $(1650-1660$ $\mathrm{cm}^{-1}$ ), amide II $\left(1550-1540 \mathrm{~cm}^{-1}\right)$ which are indicated by higher intensity of these bands when compared to normal tissues. The bands for the $\mathrm{C}-\mathrm{H}$ stretching vibration in the region around $2850 \mathrm{~cm}^{-1}$ and $\mathrm{C}=\mathrm{O}$ band near $1745 \mathrm{~cm}^{-1}$ become weaker and even disappeared. The peak of amide I band is shifted to a lower wavenumber. The intensity of the amides II bands becomes weaker. Also we found slight shifts in the positions for peaks of normal and cancer tissues.

\subsection{FT Raman Spectra for a Normal Bladder and Cancerous Tissues}

Raman spectra were obtained at Raman shift from $1800-200 \mathrm{~cm}^{-1}$ for normal and cancerous bladder tissues sampled from the seven patients. Examples of the spectra are shown in figures (5-8).

The spectra showed similar vibrational bands that were dominated by several prominent Raman peaks. For instance, the Raman bands in both tumor and normal tissues around $1270 \mathrm{~cm}^{-1}$ and $1650 \mathrm{~cm}^{-1}$ are presumably attributed to the amide III and amide I bands of proteins in the $\alpha$-helix conformation, respectively. The Raman bands around $1300 \mathrm{~cm}^{-1}$ and $1440 \mathrm{~cm}^{-1}$ are characteristic of the $\mathrm{CH}_{2} \mathrm{CH}_{3}$ bending modes of collagen and phospholipids, respectively. The peaks around $1080 \mathrm{~cm}^{-1}$ in normal and cancerous bladder tissues are due to the $\mathrm{C}-\mathrm{C}$ or $\mathrm{C}-\mathrm{O}$ stretching mode of phospholipids. The bands that dominate the Raman spectra are listed in table (2). 
Major Raman bands observed in tumor tissue and normal bladder are in agreement with the literatures that assign each band to a specific molecular vibration and are reported in references (Jansen, 1997, Jun-Kai et al. 2009, Rigas et al. 1990 and Zhiwei et al. 2003).

We can compare the changes in the spectra of normal and cancerous tissues according to Raman shift and Raman intensity. The $1440 \mathrm{~cm}^{-1}$ band is chosen as a reference point because it represents a constant and intense peak in all spectra.

Raman spectra of normal and cancerous tissues indicated significant shifts especially for amide I, $\mathrm{CH}_{2}$ and amide III bands. Raman shifts in normal and cancerous bladder tissues for samples 1-7 are illustrated in table (3).

\subsection{Comparison between the Results of FTIR and FT Raman Spectroscopy}

In many cases, FTIR required nontrivial sample preparation, such as a KBr pellet, Nujol null, and the like. These procedures are time consuming, destructive, or both. Although FTIR absorption is both popular and powerful, it does have some limitations that are fundamentals to the wavelength range involved.

In this work, Raman spectra were acquired noninvasively, and sampling procedure was simple and fast. Like FTIR, Raman scattering probes fundamental vibrations with high spectral resolution. Although the selection rules differ for FTIR and Raman, the information is similar and both are amenable to spectral libraries and fingerprinting. Raman combines the high spectral information content of FTIR with the sampling ease and convenience.

FTIR spectrum showed a wide band; therefore the shift is not sharp over the corresponding wavenumber. To compare the intensity bands between normal and the cancerous tissues using FTIR, the sample weights have to be taken very precisely.

In FT-Raman technique the spectrum showed narrow bands; therefore the comparison of Raman shifts between normal and the cancerous tissues is very clear and so this technique showed higher sensitivity for any small change in the tissue molecular structure. Direct intensity comparison between normal and cancerous tissues can be obtained, no matter how many its weights, in contrast to FTIR.

\section{Conclusions}

In this study, significant differences were found between normal and malignant bladder tissues, investigated by FTIR and FT Raman spectra, with spectra changes indicating alterations in the proteins, lipids and nucleic acids.

The results obtained from the FT Raman spectroscopy were comparable to the results obtained from the FTIR spectroscopy, and the comparison between the results showed that:

1) Raman spectroscopy is a powerful technique and act as a nondestructive analytical tool for the biochemical characterization of biological systems.

2) Raman spectroscopy is better than FTIR spectroscopy due to its sensitivity to small structural changes.

3) Investigation using FT Raman spectrometer is faster than that in FT-IR spectrometer.

4) FT Raman technique does not require wide sample preparation like FTIR spectrometer.

\section{References}

Andrade P. O., Bitar R. A., Yassoyama K., Martinho H., Santo A. M. E., Bruno P. M. and Martin A. A. (2007). Study of Normal Colorectal Tissue by FT-Raman Spectroscopy, Brazil, Springer-Verlag, Anal Bioanal Chem, 387:1643-1648.

Farshad H. Sh., Niki V., Khosrou A., Ansieh F. and Farzaneh B. R. (2007). Fourier Transform Infrared Spectroscopic Comparison of Normal and Malignant Cervical Tissue, School of Pharmacy. Iranian Journal of Pharmaceutical Research, 6 (2): 107-113.

Hammes G. G. (2005). Spectroscopy for the Biological Sciences, New Jersey, (chapter 5), pp. 92-95.

Jansen A. M. and Kortum R. R. (1997). Raman Spectroscopy for Cancer Detection: A review, Chicago, IL. USA, $19^{\text {th }}$ international Conference IEEE/EMBS Oct. 30-Nov. 2.

Jilie K. and Shaoning YU. (2007). Fourier Transform Infrared Spectroscopic Analysis of Protein Secondary Structures, Institute of Biochemistry and Cell Biology, China. ISSN 1672-9145. Acta Biochimica et Biophysica Sinica, 39(8): 549-559.

Jun-Kai D., Jing-Sen S., Xue-Jun S., Jian-Sheng W., Yi-Zhuang X., Jin-Guang W., Yuan-Fu Z. and Shi-Fu W. (2009). Fourier transform infrared spectroscopy of gallbladder carcinoma cell line, www.hbpdint.com. 
Hepatobiliary Pancreat Disn Inc, Vol 8, No 1: 75-78.

Li C., Ebenstein D., Xu C., Chapman J., Saloner D., Rapp J. and Pruitt L. (2002). Biochemical Characterization of Atherosclerotic Plaque Constituents Using FTIR Spectroscopy and Histology, Canada Student Research Award in the Undergraduate Degree Candidate Category, Canada. 28th Annual Meeting of the Society for Biomaterials, Tampa, FL, 24-27 April.

Nakamoto K. (2009). Infrared and Raman Spectra of Inorganic and Coordination Compounds, Part A: Theory and Applications in Inorganic Chemistry, Sixth Edition, Copyright by John Wiley \& Sons, Inc, New Jersey, (chapter 1), pp. 5-6.

Naumann D. (1998). Infrared and NIR Raman Spectroscopy in Medical Microbiology, Berlin, Germany, Robert Koch-Institute, Nordufer 20, 13353.

Qing-Bo L., Zhi X., Neng-Wei Z., Li Z., Fan W., Li-Min Y., Jian-Sheng W., Su Z., Yuan-Fu Z., Xiao-Si Z., Jing-Sen S. and Jin-Guang W. (2005). In vivo and in situ detection of colorectal cancer using Fourier transform infrared spectroscopy, The WJG Press and Elsevier. World Journal of Gastroenterology, ISSN 1007-9327, 11(3):327-330.

Rigas B., Morgello S., Goldman I. S., AND Wong P. T. T. (1990). Human Colorectal Cancers Display Abnormal Fourier-Transform Infrared Spectra, USA, Medical Sciences. Proc. Natl. Acad. Sci., Vol. 87: pp 8140-8144.

Stuart B. (2004). Infrared Spectroscopy Fundamentals and Applications, Copyright by John Wiley \& Sons, Canada, (chapter 1), pp. 1-3.

Venkatachalam P., Rao L. L., Kumar N. K., Jose A. and Nazee S. S. (2008). Diagnosis of Breast Cancer Based on FT-IR Spectroscopy, Perspectives in Vibrational Spectroscopy, American Institute Of Physics, USA.

Zhiwei H., Annette M., Harvey L., David M., Stephen L. and Haishan Z. (2003). Near-Infrared Raman Spectroscopy for Optical Diagnosis of Lung Cancer, Canada: Publication of the International Union Against Cancer, 107, 1047-1052. 
Table 1. The peaks positions and modes assignment of the main FTIR bands for normal and cancer bladder tissues

\begin{tabular}{|l|ll|}
\hline Wavenumber $\left(\mathrm{cm}^{-1}\right)$ & \multicolumn{2}{|l|}{ Assignment } \\
\hline $3700-3500$ & $\mathrm{O}-\mathrm{H} \quad \mathrm{N}-\mathrm{H} \quad$ hydroxyl groups \\
\hline $3300-3200$ & $\mathrm{C}-\mathrm{H} \& \mathrm{CH}_{2}$ & methylene in fatty acids \\
\hline $2930-2920$ & $\mathrm{C}-\mathrm{H} \& \mathrm{CH}_{2}$ & methylene in fatty acids \\
\hline $2850-2860$ & $\mathrm{C}=\mathrm{O} \quad$ esters \\
\hline $1740-1750$ & $\mathrm{C}=\mathrm{O} \quad$ amide I $\quad$ (Proteins) \\
\hline $1650-1660$ & $\mathrm{C}-\mathrm{N} \quad$ amide II (proteins) \\
\hline $1540-1550$ & $\mathrm{C}-\mathrm{H} \& \mathrm{CH}_{2}$ & methylene (Lipids and $\backslash$ or Proteins) \\
\hline $1450-1460$ & $\mathrm{Amide}$ III & (proteins) \\
\hline $1310-1240$ & $\mathrm{P}=\mathrm{O} \quad$ PO & phosphodiesters \\
\hline $1088-1040$ &
\end{tabular}

Table 2. Assignments of major Raman spectra of normal and cancerous bladder tissues

\begin{tabular}{|c|c|c|}
\hline Peaks position $\left(\mathrm{cm}^{-1}\right)$ & Vibrational Mode & Major Assignment \\
\hline $1650-1680$ & $v(\mathrm{C}=\mathrm{O})$ of amide $\mathrm{I}, \mathrm{v}(\mathrm{C}=\mathrm{C})$ & proteins ( $\alpha$-helix), lipids \\
\hline $1440-1470$ & $\delta\left(\mathrm{CH}_{2}\right)$ & $\begin{array}{l}\text { lipids, carbohydrates, proteins and } \\
\text { pentose }\end{array}$ \\
\hline $1260-1275$ & $\begin{array}{c}v(\mathrm{C}-\mathrm{N}) \text { of amide III, } \\
v(=\mathrm{C}-\mathrm{H})\end{array}$ & proteins ( $\alpha$-helix), lipids \\
\hline $1040-1100$ & $\begin{array}{c}v(\mathrm{C}-\mathrm{C}) \text { or } \quad v(\mathrm{C}-\mathrm{O}) \\
v(\mathrm{C}-\mathrm{C}) \text { or } \quad v\left(\mathrm{PO}_{2}\right), \\
v(\mathrm{C}-\mathrm{N}), \quad v(\mathrm{O}-\mathrm{P}-\mathrm{O})\end{array}$ & $\begin{array}{c}\text { lipids, nucleic acids, proteins, } \\
\text { carbohydrates }\end{array}$ \\
\hline
\end{tabular}


Table 3. Comparison between Raman shifts in normal and cancerous bladder tissues for samples 1-7

\begin{tabular}{|c|c|c|}
\hline \multirow{2}{*}{ Sample number } & Normal tissue & Cancerous Tissue \\
\hline & Raman Shift $\left(\mathrm{cm}^{-1}\right)$ & Raman Shift $\left(\mathrm{cm}^{-1}\right)$ \\
\hline \multirow{4}{*}{1} & 1654 & 1651 \\
\hline & 1442 & 1440 \\
\hline & 1265 & 1278 \\
\hline & 1078 & 1078 \\
\hline \multirow{4}{*}{2} & 1630 & 1651 \\
\hline & 1444 & 1448 \\
\hline & 1279 & 1272 \\
\hline & 1067 & 1047 \\
\hline \multirow{4}{*}{3} & 1634 & 1658 \\
\hline & 1470 & 1458 \\
\hline & 1285 & 1279 \\
\hline & 1070 & 1101 \\
\hline \multirow{4}{*}{4} & 1660 & 1648 \\
\hline & 1456 & 1449 \\
\hline & 1298 & 1259 \\
\hline & 1097 & 1097 \\
\hline \multirow{4}{*}{5} & 1649 & 1642 \\
\hline & 1446 & 1455 \\
\hline & 1279 & 1274 \\
\hline & 1077 & 1086 \\
\hline \multirow{4}{*}{6} & 1662 & 1665 \\
\hline & 1457 & 1448 \\
\hline & 1287 & 1267 \\
\hline & 1083 & 1102 \\
\hline \multirow{4}{*}{7} & 1657 & 1655 \\
\hline & 1444 & 1441 \\
\hline & 1266 & 1267 \\
\hline & 1075 & 1095 \\
\hline
\end{tabular}




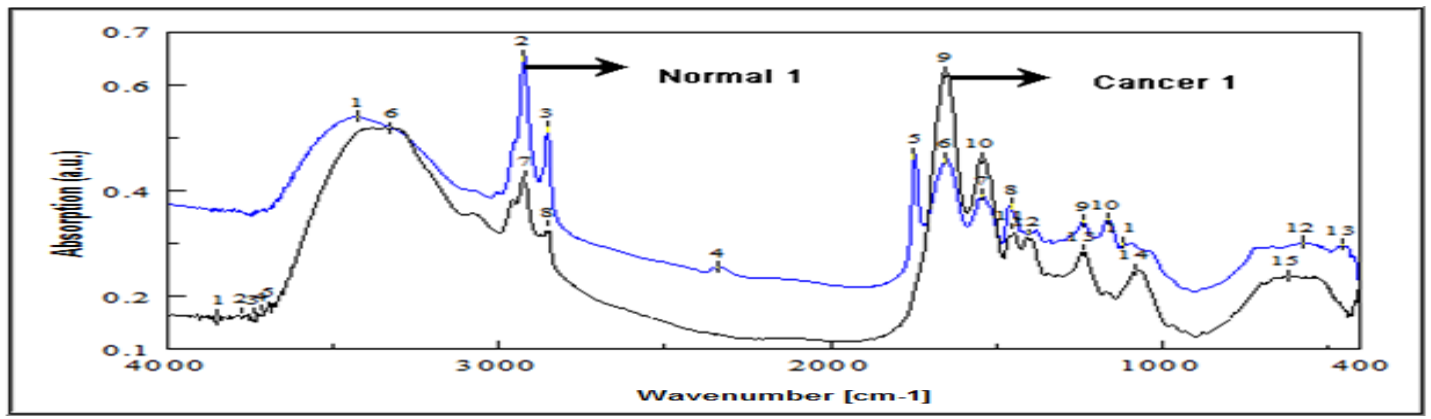

Figure 1. FTIR spectra of normal and cancerous bladder from patient number (1)

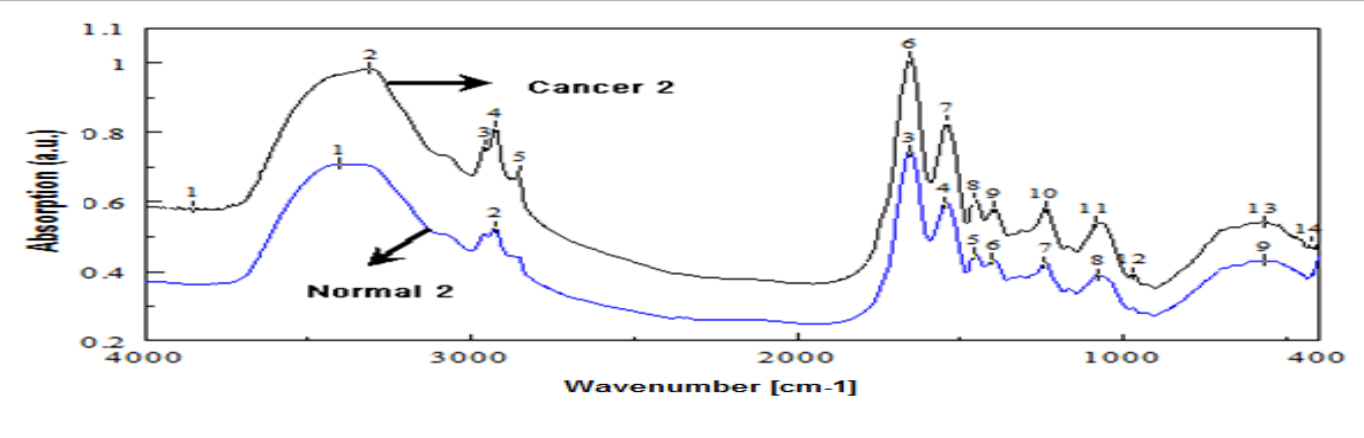

Figure 2. FTIR spectra of normal and cancerous bladder from patient number (2)

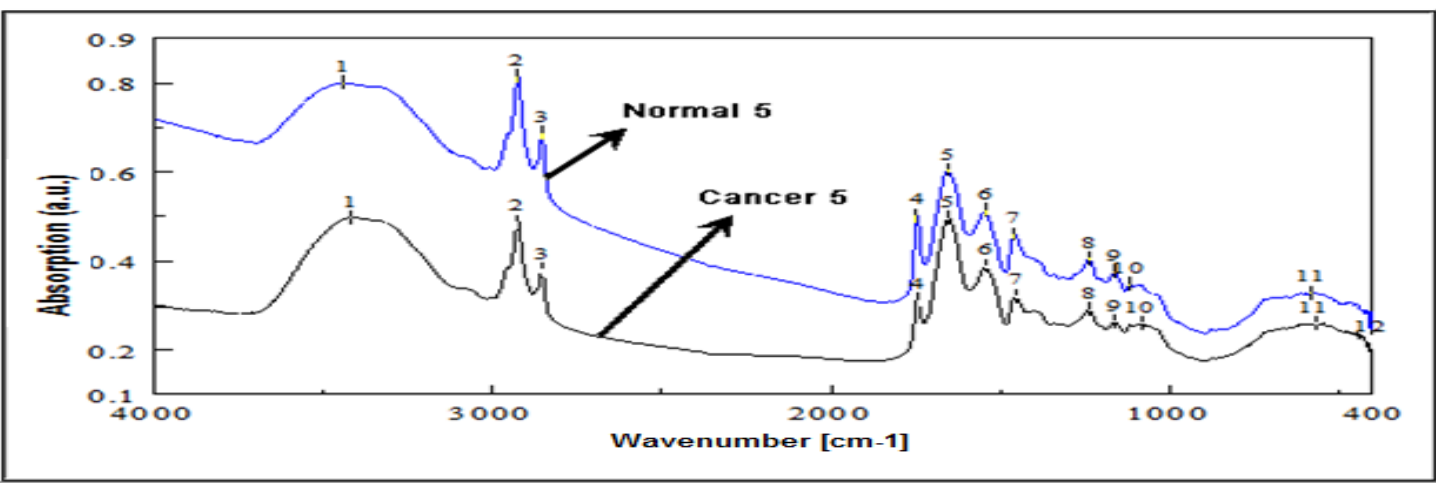

Figure 3. FTIR spectra of normal and cancerous bladder from patient number (5)

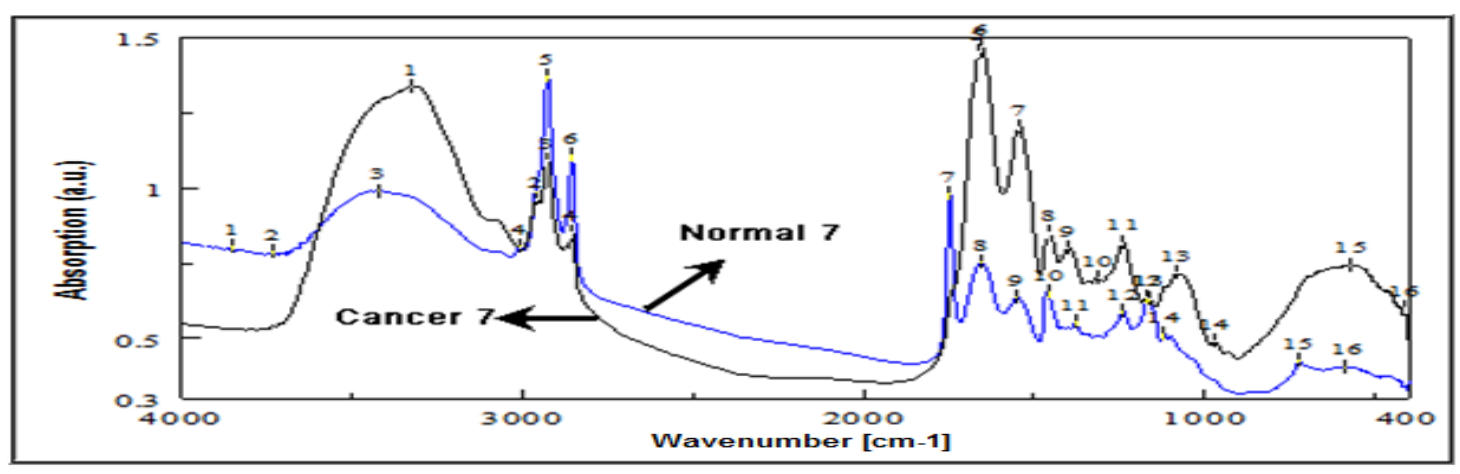

Figure 4. FTIR spectra of normal and cancerous bladder from patient number (7) 


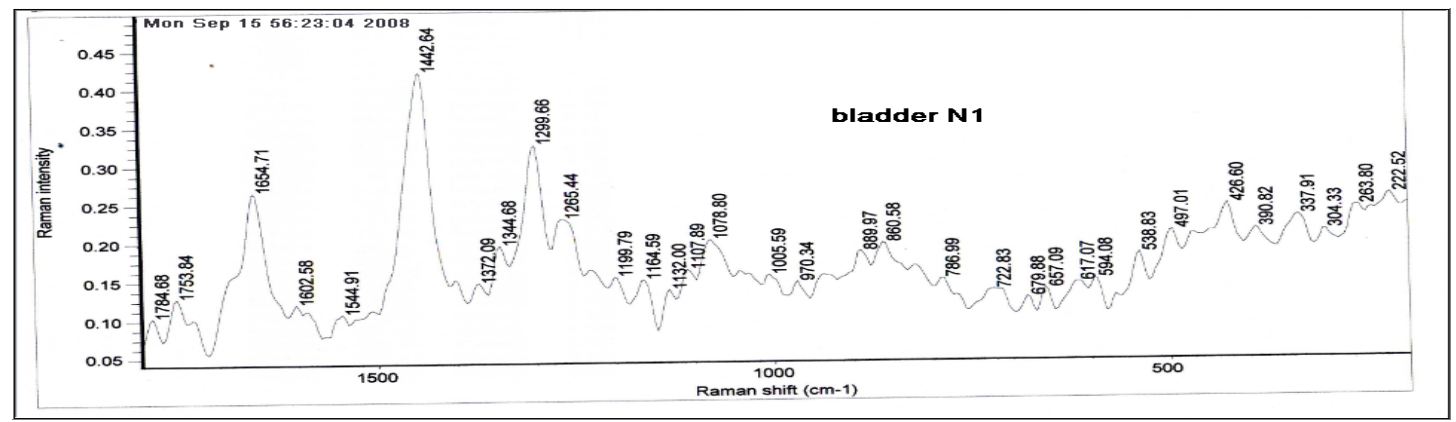

Figure 5-a. Raman Spectrum of Normal Bladder (patient 1)

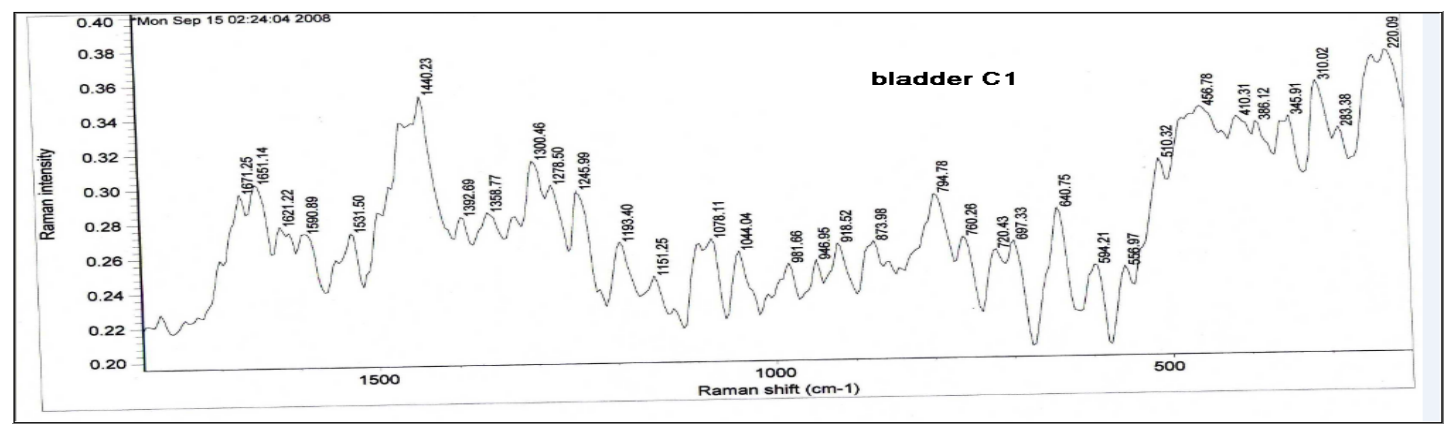

Figure 5-b. Raman Spectrum of Cancerous Bladder (patient 1)

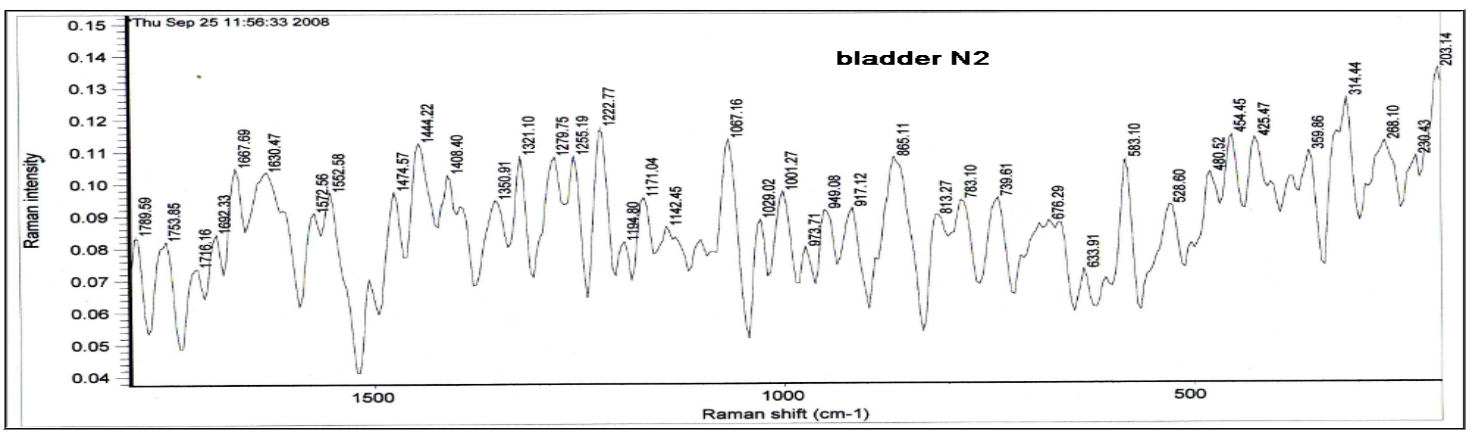

Figure 6-a. Raman Spectrum of Normal Bladder (patient 2)

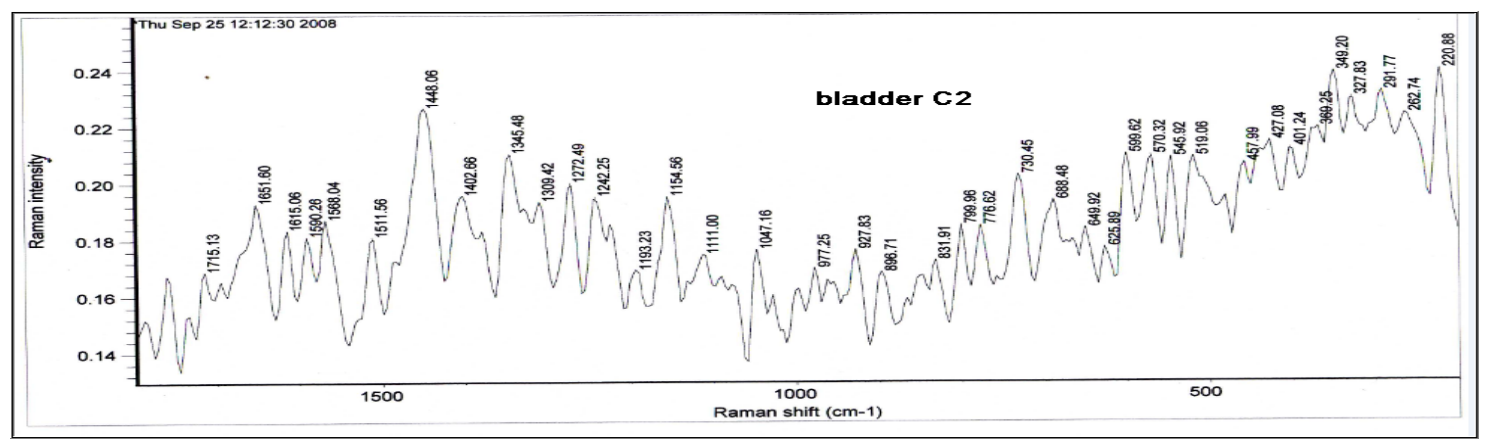

Figure 6- b. Raman Spectrum of Cancerous Bladder (patient 2) 


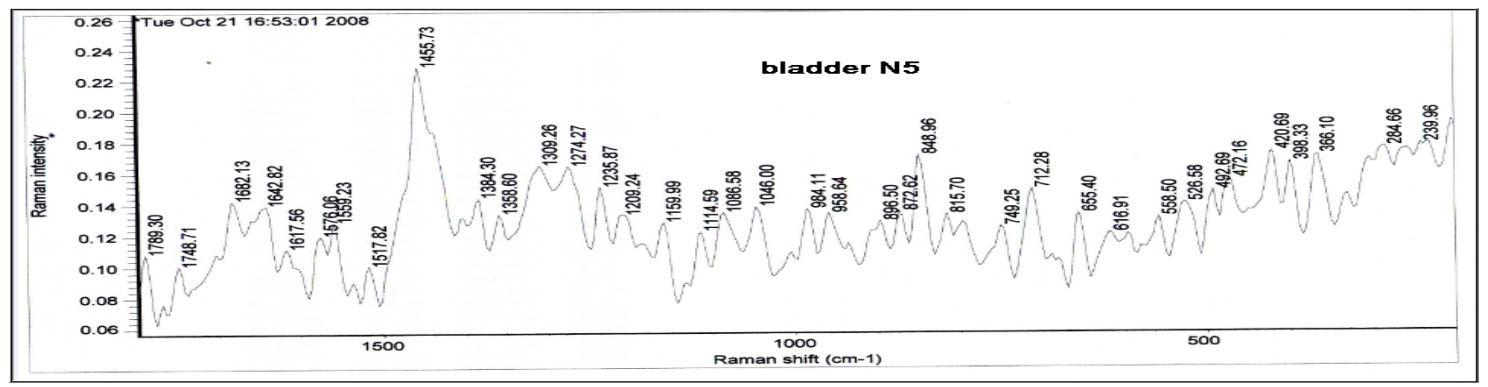

Figure 7-a. Raman Spectrum of Normal Bladder (patient 5)

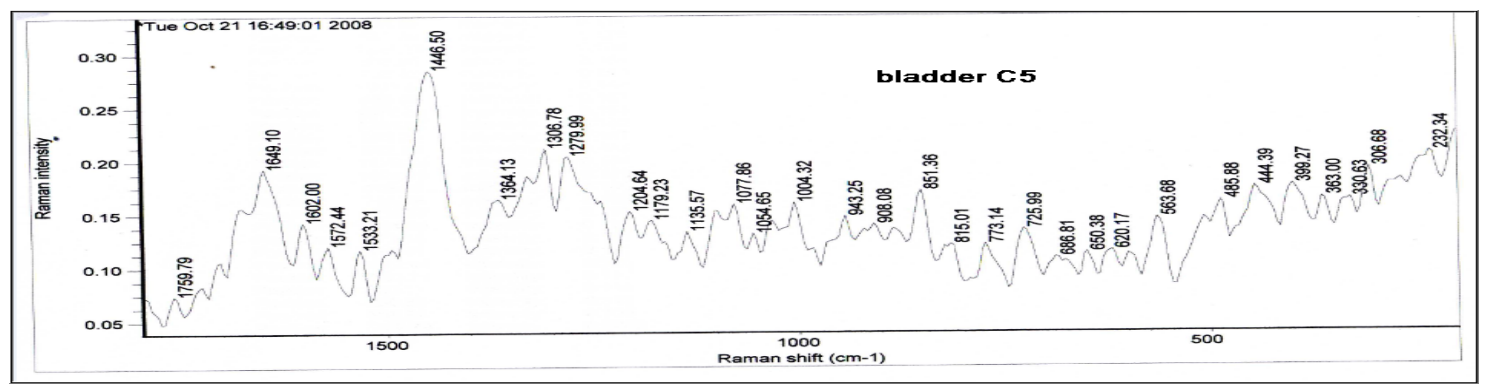

Figure 7- b. Raman Spectrum of Cancerous Bladder (patient 5)

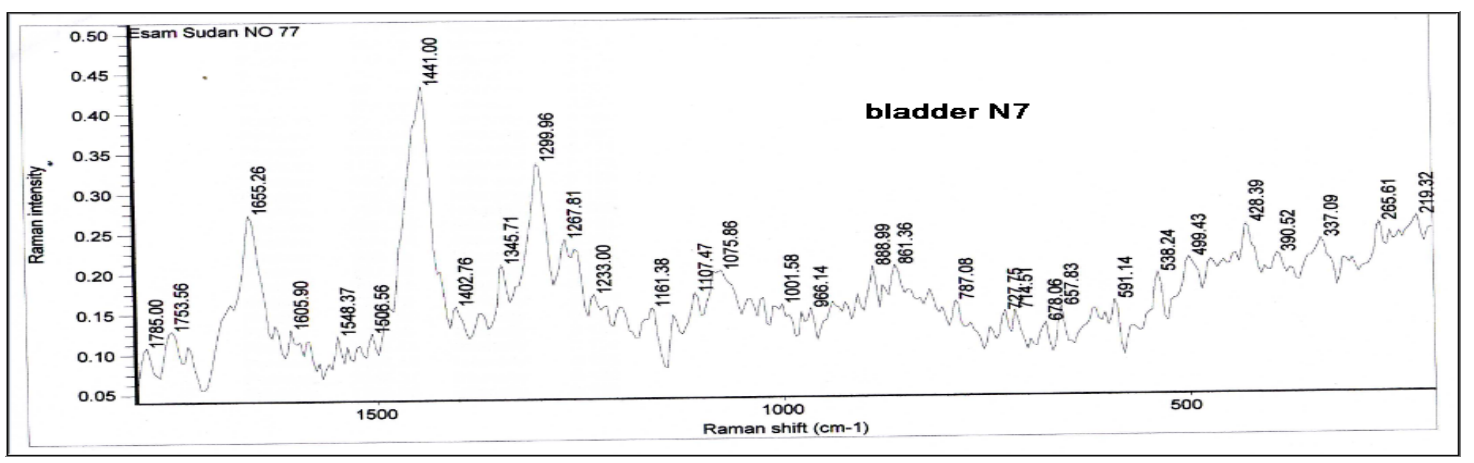

Figure 8-a. Raman Spectrum of Normal Bladder (patient 7)

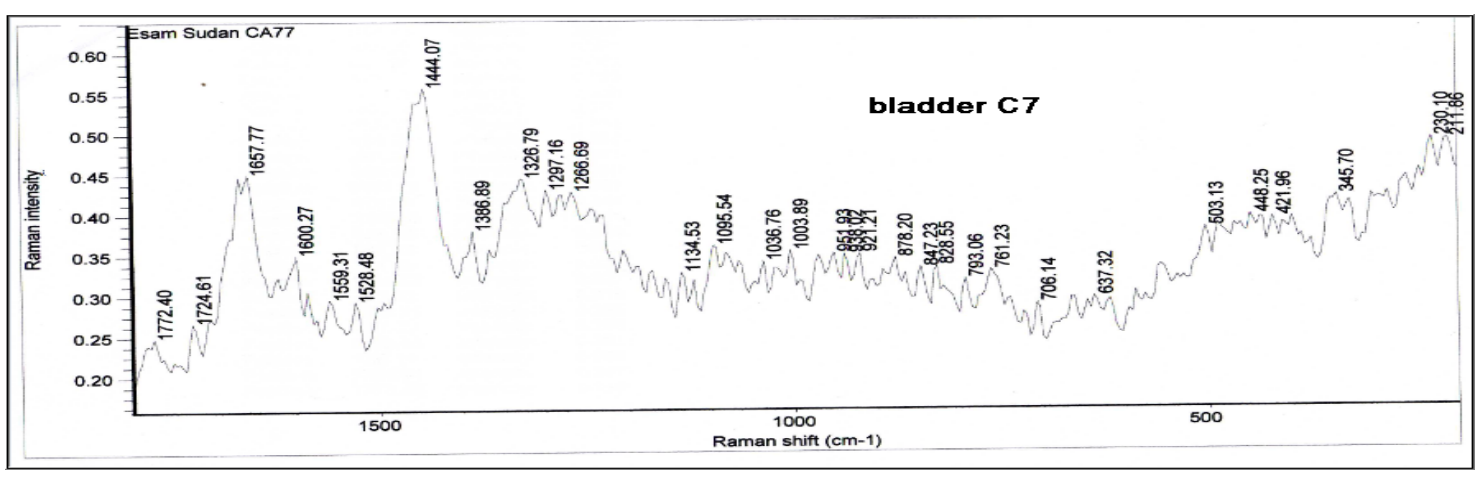

Figure 8-b. Raman Spectrum of Cancerous Bladder (patient7) 